\title{
The effect of the feed-to-buffer ratio on bacterial diversity and ruminal fermentation in single-flow continuous-culture fermenters
}

\author{
G. Cantalapiedra-Hijar, ${ }^{\star}$ D. R. Yáñez-Ruiz, ${ }^{\star}$ C. J. Newbold,† and E. Molina-Alcaide*1 \\ *Estación Experimental del Zaidín (Consejo Superior de Investigaciones Científicas), Profesor Albareda, 1, 18008 Granada, Spain \\ †Institute of Biological, Environmental and Rural Sciences (IBERS), Aberystwyth University, Llanbadarn Campus, SY23 3 AL, Aberystywth, UK
}

\begin{abstract}
Eight single-flow continuous-culture fermenters were used in a completely randomized block design with a 2 $\times 4$ factorial arrangement of treatments to investigate the effects of the feed-to-buffer ratio $(\mathrm{F} / \mathrm{B})$ on ruminal fermentation, the diversity and community structure of bacteria, nutrient digestibility, and $\mathrm{N}$ metabolism. Four diets with forage-to-concentrate ratios of 70:30 or 30:70 with alfalfa or grass hay as forage were supplied to fermenters twice per day at 2 different $\mathrm{F} / \mathrm{B}(23.5$ and $35 \mathrm{~g}$ of $\mathrm{DM} / \mathrm{L})$. The dilution rate was kept constant (5.3\%) among all fermenters by infusing the same volume of buffer. An increase in the total volatile fatty acid (VFA) concentration and a decrease in the average $\mathrm{pH}$ were observed with an increased $\mathrm{F} / \mathrm{B}$. In addition, the molar proportions of all individual VFA found in fermenters differed, depending on the F/B. A terminal restriction fragment length polymorphism analysis showed that the community structure and diversity of bacteria were highly influenced by the $\mathrm{F} / \mathrm{B}$. Both diversity and the number of peaks in the electropherograms were lower in most fermenters receiving diets at a high F/B, whereas the similarity percentage of the bacterial communities across diets was higher as the $\mathrm{F} / \mathrm{B}$ increased. Moreover, the high reduction of neutral detergent fiber digestibility $(15.3 \% \pm 3.65)$ in fermenters with high $\mathrm{F} / \mathrm{B}$ suggested a $\mathrm{pH}$-related decrease in the cellulolytic bacterial community as the $\mathrm{F} / \mathrm{B}$ increased. The crude protein degradation found in fermenters receiving diets with a high $\mathrm{F} / \mathrm{B}$ was lower compared with that from fermenters with a low $\mathrm{F} / \mathrm{B}$. The VFA concentration and purine bases flow response patterns to diets were similar to in vivo conditions only in the case of fermenters with a low F/B. The results suggested that the community structure and diversity of bacteria, as well as the in vitro fermentation parameters, may be affected by the $\mathrm{F} / \mathrm{B}$ that is used, most likely through a $\mathrm{pH}$ effect. In addition, several fermentation parameters
\end{abstract}

Received March 13, 2010.

Accepted November 5, 2010.

${ }^{1}$ Corresponding author: molina@eez.csic.es showed different response patterns to diets according to the F/B used. Therefore, the amount of feed supplied to single-flow continuous-culture fermenters in which $\mathrm{pH}$ is not under control should be carefully chosen according to the volume of buffer infused for the purpose of simulating ruminal fermentation.

Key words: continuous-culture fermenter, feed/buffer, ruminal fermentation, bacterial diversity

\section{INTRODUCTION}

Continuous-culture fermenters (CCF) have been widely used in nutritional research to study ruminal fermentation under carefully controlled conditions (Griswold et al., 2003; Castillejos et al., 2005; MolinaAlcaide et al., 2009). In particular, studies with CCF have recently shown that the average $\mathrm{pH}$ (Calsamiglia et al., 2002), the time during which $\mathrm{pH}$ values are suboptimal (Cerrato-Sánchez et al., 2008), and the extent of $\mathrm{pH}$ variation (Wales et al., 2004) are important factors influencing ruminal fermentation. In addition, the $\mathrm{pH}$ in the fermenters has been thought to be responsible for shifts in the rumen bacterial population (Yang et al., 2002; Calsamiglia et al., 2008; Carro et al., 2009). These findings underline the need to maintain in vitro $\mathrm{pH}$ values across time that are as close as possible to those in the rumen of animals consuming similar diets to sustain similar compositions and structures of microbial community and, thus, to accurately simulate ruminal fermentation (Devant et al., 2001; Colombatto et al., 2003). However, in most of the studies carried out with $\mathrm{CCF}$, the $\mathrm{pH}$ was set to be constant or within a narrow range (Dahlberg et al., 1988; Mansfield et al., 1995; Griswold et al., 2003). Fixed pH values may reduce shifts in microbial species as the diet composition changes and could explain some differences found between the rumen and fermenters in direct comparative studies (Hannah et al., 1986; Mansfield et al., 1995).

The results of some studies (Hoover et al., 1976; Crawford et al., 1980; Carro et al., 2009; Muetzel et al., 2009) seem to indicate an effect of the feed-tobuffer ratio (F/B; g of DM feed/L of buffer) on the $\mathrm{pH}$ reached in $\mathrm{CCF}$, and although this ratio has been 
proposed as being responsible for $\mathrm{pH}$ changes (Carro et al., 2009), to our knowledge, no studies have analyzed the effect of different F/B. Because many discrepancies in fermentation between rumens and CCF have been clearly attributed to differences in $\mathrm{pH}$ values (Mansfield et al., 1995; Molina-Alcaide et al., 2009), the F/B should be carefully chosen in fermenters in which $\mathrm{pH}$ is not under control. However, important variations do exist among CCF studies, with $\mathrm{F} / \mathrm{B}$ ranging from $10 \mathrm{~g}$ of DM/L (Muetzel et al., 2009) to more than $65 \mathrm{~g}$ of DM/L (Molina-Alcaide et al., 2009). This lack of uniformity could be due to differences in the diet quality, the saliva composition and the CCF model used, but even using similar conditions, the $\mathrm{F} / \mathrm{B}$ varies among studies [Tapia et al., $2002(\mathrm{~F} / \mathrm{B}=50.6)$; Carro et al., $2009(\mathrm{~F} / \mathrm{B}=31.8)]$.

The objective of this study was to determine to what extent 2 different F/B (23.5 and $35 \mathrm{~g}$ of DM/L) would affect the bacterial diversity and structure together with the in vitro fermentation pattern and $\mathrm{N}$ metabolism. Additionally, the present study aimed to determine the ability of single-flow continuous-culture fermenters to discriminate between different dietary treatments similarly to goat rumen. Details of an in vivo study with nonlactating dairy goats receiving the same experimental diets used in the present study have been previously reported (Cantalapiedra-Hijar et al., 2009).

\section{MATERIALS AND METHODS}

\section{Apparatus, Diets, and Animals}

Four 12-d incubation runs were carried out using 8 single-flow CCF, following the model of Miettinen and Setälä (1989), with an effective volume of 1,000 mL. The experimental diets were grass hay-high forage (GF), composed of $70 \%$ of grass hay $(\mathbf{G})$ and $30 \%$ of concentrate $(\mathbf{C})$; grass hay-high concentrate $(\mathbf{G C})$, composed of $30 \%$ of $\mathrm{G}$ and $70 \%$ of C; alfalfa hay-high forage (AF), composed of $70 \%$ of alfalfa hay (A) and $30 \%$ of C; and alfalfa hay-high concentrate (AC), composed of $30 \%$ of $\mathrm{A}$ and $70 \%$ of $\mathrm{C}$ on a DM basis. Each diet was tested at 2 different $\mathrm{F} / \mathrm{B}$ levels, a low (23.5 g of DM/L) and a high (35 g of DM/L) level, resulting in 8 treatments allocated to each of the 8 fermenters used in every incubation run. The fermenters were inoculated with 700 $\mathrm{mL}$ of rumen fluid from goats previously adapted for $21 \mathrm{~d}$ to the same diets provided to the corresponding fermenter (Cantalapiedra-Hijar et al., 2009). Each of the 4 in vitro periods in this work was run concurrently with its respective in vivo period (Cantalapiedra-Hijar et al., 2009). The rumen contents from goats were collected $2 \mathrm{~h}$ after feeding, immediately transported to the laboratory in thermal bottles, and strained through 4 layers of cheesecloth. Rumen fluid from each of the 4 rumen-fistulated goats was inoculated within $30 \mathrm{~min}$ after collection into 2 fermenters, each one receiving the same diet that the inoculum donor received (Mansfield et al., 1995) at one of the 2 studied F/B. Because the 4 goats were adapted to diets according to a $4 \times 4$ Latin square design (Cantalapiedra-Hijar et al., 2009), none of the 4 single-flow CCF receiving the same treatment across the 4 incubation runs shared the same donor of rumen fluids. The hay was chopped (theoretical length of cut was $1 \mathrm{~cm}$ ), and the concentrate was given as small pellets $(12 \times 4 \mathrm{~mm})$. The management of the animals and the experimental procedures were conducted by trained personnel in strict accordance with Spanish guidelines (Act No. 1201/2005 of 10 October 2005) regarding the protection of experimental animals.

\section{Experimental Procedure and Sampling}

Treatments were arranged as a $2 \times 4$ factorial with $\mathrm{F} / \mathrm{B}$ and diet as the main effects. Each combination of $\mathrm{F} / \mathrm{B} \times$ diet was used once in each of the 4 incubation runs. The diet was supplied daily in 2 equal portions at 0900 and $1500 \mathrm{~h}$. The flow through all fermenters was maintained by continuous infusion of McDougall (1948) artificial saliva (approximately $53 \mathrm{~mL} / \mathrm{h}$ ) to achieve an outflow rate $(5.3 \%)$ similar to that of other studies (Tapia et al., 2002; Carro et al., 2009; Molina-Alcaide et al., 2009), and $\mathrm{CO}_{2}$ was continuously infused into the fermentation flask to maintain anaerobic conditions. Two different $\mathrm{F} / \mathrm{B}$ were achieved by changing the feed input while keeping constant the volume of artificial saliva infused. Effluent from each fermenter was collected in a vessel maintained in a $3^{\circ} \mathrm{C}$ bath to prevent microbial growth.

The duration of each incubation run lasted $7 \mathrm{~d}$ for adaptation and $5 \mathrm{~d}$ for sampling. Every day, effluents were removed, and their weights and volumes were recorded. From d 8 through 11, effluents were collected and filtered through 4 layers of cheesecloth, and two 5 - $\mathrm{mL}$ aliquots were taken and stored at $-20^{\circ} \mathrm{C}$ for $\mathrm{NH}_{3}-$ $\mathrm{N}$ and VFA analyses. At the end of the trial, composite subsamples from 3 sampling days were made, and 1 aliquot was collected for the total $\mathrm{N}$ determination. The remainder was freeze-dried before analysis for DM, OM, NDF, ADF, ether extract (EE), and purine base (PB) contents.

Twice per day, the $\mathrm{pH}$ in the fermentation flask was measured immediately before feeding. On $\mathrm{d} 11$, the $\mathrm{pH}$ of the content of the fermenters was measured at 0 , $2,4,6,8,10$, and $12 \mathrm{~h}$ after the morning feeding. In addition, $2 \mathrm{~h}$ after the morning feeding, a $2-\mathrm{mL}$ aliquot was taken from the content of the fermenters for the subsequent analysis of the community structure and 
diversity of the bacteria. The molecular analysis was limited to samples collected from the 2 first incubation runs $(\mathrm{n}=16)$ because of the cost of the terminal RFLP (T-RFLP) analysis. On d 12, the total effluent was collected for bacterial pellet isolation following the procedure described by Martín-Orúe et al. (1998), with minor modifications. The effluent was squeezed through 4 layers of cheesecloth and a 50-mm nylon filter was used to trap particulate matter and let the liquid phase pass through (step 1). The solid residue obtained was resuspended in its weight of a $0.85 \%$ saline solution at $39^{\circ} \mathrm{C}$. After shaking, the suspension was filtered again (step 2). Solid-associated bacteria were separated from the residue obtained in step 2 by diluting the residue in the $0.85 \%$ saline solution with $0.1 \%$ of methylcellulose at $39^{\circ} \mathrm{C}$, shaking it for $30 \mathrm{~min}$ and filtering it (step 3). The solid residue obtained in step 3 was finally diluted in a $0.85 \%$ saline solution and kept at $4^{\circ} \mathrm{C}$ for $24 \mathrm{~h}$ before its homogenization with a Waring Blender (Waring, New Hartford, CT) and its filtration (step 4). Filtrates obtained in Steps 1, 2, 3, and 4 were pooled together and subjected to a differential centrifugation (500 $\times g$ for 5 min followed by 2 consecutive centrifugations of the supernatant fractions at $20,000 \times g$ for $20 \mathrm{~min}$ at $4^{\circ} \mathrm{C}$ ). The bacterial pellets isolated (bacteria from effluent; EB) were freeze-dried and then ground to a fine powder with a mortar and pestle before their analysis for DM, OM, N, and PB contents.

\section{Chemical Analyses}

Dry matter (method ID 934.01), ash (method ID 942.05), N (method ID 984.13), and EE (method ID 7.045) contents were determined according to the AOAC (2005). The analyses of NDF and ADF were carried out according to Van Soest et al. (1991) using an Ankom ${ }^{20}$ fiber analyzer unit (Ankom Technology Corp., Macedon, NY). A heat-stable $\alpha$-amylase was used for NDF analysis, and both NDF and ADF were expressed exclusive of residual ash. The ADL was determined by the solubilization of cellulose with $75 \%$ of sulfuric acid. The in vitro DM, OM, and CP digestibility of the diet ingredients was determined according to the procedure described by Tilley and Terry (1963), using an Ankom Daisy Incubator (Ankom Technology Corp.).

Aliquots of the strained effluents were thawed in the refrigerator overnight and centrifuged at $4^{\circ} \mathrm{C}$ and 20,000 $\times g$ for $20 \mathrm{~min}$, and the supernatant was analyzed for VFA and $\mathrm{NH}_{3}-\mathrm{N}$. Individual VFA were analyzed (Isac et al., 1994) by GC. The $\mathrm{NH}_{3}-\mathrm{N}$ concentration was determined by a colorimetric method (Weatherburn, 1967).

Purine bases (adenine and guanine) in effluents and bacterial pellets were determined following the method described by Balcells et al. (1992) using HPLC, which consisted of a multisolvent delivery system (model 510; Waters, Millipore, Billerica, MA), an injector (WatersTM 717 plus Autosampler, Waters), a multiwavelength detector (model 481; Lambda-Max, LC spectrophotometer, Waters, set to $205 \mathrm{~nm}$ ) and a double 4.0 $\mathrm{mm} \times 250 \mathrm{~mm}$ C18 ODS-2 analytical column (Waters Spherisorb). The purine bases were quantified by peak integration using the Waters HPLC systems software Millenium32.

\section{Terminal RFLP Analysis}

In order to analyze the similarity between bacterial communities, samples of the fermenter contents were freeze-dried and kept at $-80^{\circ} \mathrm{C}$ for 5 min before being beaten at maximum speed in a Minibeadbeater (Biospec Products Inc., Bartlesville, OK) for 1 min. The total DNA was then extracted using a Qiagen QIAmp DNA stool mini kit (Qiagen Ltd., West Sussex, UK), following the manufacturer's instructions but using a high temperature $\left(95^{\circ} \mathrm{C}\right)$ for the step of lysis incubation. The PCR was used to amplify approximately 1,300 bp of the $16 \mathrm{~S}$ rRNA gene before T-RFLP analysis. The amplification reactions contained $0.05 \mathrm{U} / \mu \mathrm{L}$ Taq DNA polymerase (Promega Corporation, Madison, WI), $1 \times$ reaction buffer as supplied by the manufacturer, 1.5 $\mathrm{m} M \mathrm{MgCl}_{2}, 0.25 \mu \mathrm{mol}$ of each primer, $0.2 \mathrm{mmol}$ of each deoxyribonucleotide triphosphate (dNTP), and $1 \mu \mathrm{L}$ of extracted DNA in a final volume of $25 \mu \mathrm{L}$. The bacterial-specific primer pairs used (Hongoh et al., 2005) were cyanine-labeled 27F (5'-AGA GTT TGA TCC TGG CTG AG-3') and unlabeled 1389R (5'-AGG GGG GGT GTG TAG AAG-3'). Reactions were conducted in a Biorad MyCycler thermal cycler (Bio-Rad Laboratories, Inc., Hercules, CA) with an initial denaturation at $94^{\circ} \mathrm{C}$ for $5 \mathrm{~min}$, followed by 25 cycles at $94^{\circ} \mathrm{C}$ for $1 \mathrm{~min}, 55^{\circ} \mathrm{C}$ for $1 \mathrm{~min}$, and $72^{\circ} \mathrm{C}$ for $1 \mathrm{~min}$, with a final extension carried out at $72^{\circ} \mathrm{C}$ for $2 \mathrm{~min}$. The PCR product was purified on a Millipore MultiScreen $\mathrm{PCR}_{\mu 96}$ plate (with a 20-inch $\mathrm{Hg}$ vacuum). To standardize the digestion of DNA, the concentration of DNA in each sample was determined by spectrophotometry (Nanodrop ND-1000 spectrophotometer, NanoDrop Technologies, Rockland, $\mathrm{DE}$ ) and then diluted to a concentration of $20 \mathrm{ng} / \mu \mathrm{L}$ (Osborn et al., 2000). The restriction enzyme digestion was performed using HaeIII, HhaI, MspI, and RsaI (Promega Corp., Madison, WI) in single-enzyme digestions at $0.25 \mathrm{U} / \mu \mathrm{L}$ (HaeIII) and $0.15 \mathrm{U} / \mu \mathrm{L}$ (HhaI, MspI, and $R s a \mathrm{I}$ ) for $5 \mathrm{~h}$ at $37^{\circ} \mathrm{C}$. The digestion product was then purified and precipitated by washing once with $95 \%$ of ethanol at $-80^{\circ} \mathrm{C}$ and twice with $70 \%$ ethanol at $-20^{\circ} \mathrm{C}$ with successive centrifugations $(3,000 \times g$ for $15 \mathrm{~min}$ at $4^{\circ} \mathrm{C}$ ) and decantations. The purified product 
was dried at room temperature until the ethanol was completely removed, resuspended in $35 \mu \mathrm{L}$ of a sodium lauryl sulfate buffer solution (Beckman Coulter Inc., Fullerton, CA) and added to $0.2 \mu \mathrm{L}$ of DNA standard 600. Terminal restriction fragments (TRF) were separated by capillary gel electrophoresis according to their size. The TRF sizes were estimated by comparing their retention times with those of the DNA internal standard, using the local southern algorithm, and aligned by the amplified fragment length polymorphism facility in the CEQ 8000 software. To retrieve the maximum peaks number, data were exported with minimum values of $1 \%$ for slope threshold and $0 \%$ for relative peak height filtering values within the CEQ 8000 software. Because the differential retrieval of DNA concentration from sample washing and loading inaccuracies may occur, peak areas were converted to relative values, minimizing the correlation between the total peak area and the number of peaks (Sait et al., 2003). In order to remove most of the noisy peaks as well as uncertain peaks, such as those possibly produced by PCR or enzyme digestion, and to retain all major peaks, a percentage threshold (cut-off value) for a relative area of $0.5 \%$ was applied (Zhang et al., 2008). The analysis of TRF profiles generated from the 4 single-enzyme digestions was performed with Bray Curtis distances, and dendrograms were constructed with the Ward method (SAS Institute, Inc.) in the CAP 4 software (Pisces Conservation Ltd., Lymington, Hampshire, UK). A similarity percentage (SIMPER) was used to compare the homology in bacterial communities within samples of low- and high-F/B fermenters. A Shannon diversity index, which accounts for both the abundance and the evenness of the species present, was calculated on every sample (Shannon and Weaver, 1963).

\section{Calculations and Statistical Analysis}

True DM and OM digestibility was calculated by correcting the apparent digestibility values with microbial DM and OM content, respectively. The apparent DM digestibility in fermenters was calculated as described by Crawford et al. (1980) with corrections for buffer salts lost during freeze-drying. The true NDF and ADF digestibility as well as the apparent digestibility of OM and NFC were calculated from the input and output data. The NFC was calculated as $\mathrm{NFC}=\mathrm{OM}-(\mathrm{NDF}$ $+\mathrm{CP}+\mathrm{EE})$. The microbial $\mathrm{N}$ flow from the fermenter was estimated by multiplying the total non-ammonia $\mathrm{N}$ in the effluent by the ratio of $\mathrm{PB} / \mathrm{N}$ in the effluent and in EB pellets. The efficiency of microbial protein synthesis was calculated as grams of estimated microbial N flow per $1 \mathrm{~kg}$ of $\mathrm{OM}$ that is truly digested.
Data were analyzed according to the general linear model procedure of SPSS for Windows, version 15.0 (2007; SPSS Inc., Chicago, IL), with a $2 \times 4$ factorial arrangement of treatments in a completely randomized block design. The period (block) was designated as a random effect, whereas $\mathrm{F} / \mathrm{B}$, diet, and the interaction between $\mathrm{F} / \mathrm{B}$ and diet were set as fixed effects. The $\mathrm{pH}$ values across time were analyzed, while taking the correlation among repeated measures from the same rumen fluid inoculum into account, and accordingly, a linear mixed model (Littell et al., 1998) was used. The linear mixed model included the effect of time after feeding as well as its interaction with diet and $\mathrm{F} / \mathrm{B}$. The time after feeding was considered the repeated factor, and each CCF within the diet was considered the subject. For each variable analyzed, data were subjected to 3 different covariance structures: variance components, compound symmetry, and unstructure. The covariance structure that yielded the largest Schwarz Bayesian was considered to be the most desirable for analysis (Littell et al., 1998). Significance was determined at $P<0.05$. When significant differences were detected, differences among means were tested using the Tukey comparison test. The Shannon indices, as well as the average $\mathrm{pH}$ values, were tested for significant differences between the 2 main detected clusters using one-way ANOVA.

\section{RESULTS AND DISCUSSION}

The $\mathrm{pH}$ in the rumen depends on the amount of incoming saliva and the accumulation of organic acids produced, particularly VFA and lactic acid (Church, 1976). In CCF, the $\mathrm{pH}$ values rely on similar factors. However, the volume of buffer as artificial saliva entering a fermenter usually does not show a response to diet composition as would occur in vivo (Colombatto et al., 2003). The volume of buffer is normally chosen to promote a particular liquid dilution rate (Meng et al., 1999; Martínez et al., 2009). The F/B used in CCF could have a significant effect on $\mathrm{pH}$ values (Hoover et al., 1976; Muetzel et al., 2009). The F/B expresses the quotient of 2 of the main factors determining the concentration of the end products of fermentation for a given diet: the amount of fermentable OM supplied per unit of a fermenter's effective volume and the buffering capacity of the system due to the continuous infusion of artificial saliva. Because the aim of this work was to study the effect of the $\mathrm{F} / \mathrm{B}$ on ruminal fermentation while keeping other operating variables constant, 2 different $\mathrm{F} / \mathrm{B}$ were achieved by changing only the amount of feed supplied to the fermenters, avoiding differences in responses due to effects linked to the liquid dilution rate. The experimental diets (Table 1) used in 
Table 1. Chemical composition $(\mathrm{g} / \mathrm{kg}$ of $\mathrm{DM})$ and in vitro digestibility $(\mathrm{g} / \mathrm{g})$ of the experimental diets

\begin{tabular}{lcccc}
\hline & \multicolumn{3}{c}{ Diet $^{1}$} \\
\cline { 2 - 5 } Item & GF & GC & AF & AC \\
\hline $\mathrm{DM}, \mathrm{g} / \mathrm{kg}$ of fresh matter & 903 & 901 & 896 & 898 \\
$\mathrm{OM}$ & 925 & 913 & 897 & 901 \\
$\mathrm{CP}$ & 126 & 168 & 194 & 197 \\
$\mathrm{Ether} \mathrm{extract}$ & 21.2 & 28.0 & 20.4 & 27.6 \\
$\mathrm{NDF}$ & 453 & 382 & 398 & 359 \\
$\mathrm{ADF}$ & 230 & 174 & 263 & 188 \\
Acid detergent lignin & 35.5 & 30.7 & 59.2 & 40.8 \\
Gross energy, MJ/kg of DM & 18.6 & 18.4 & 18.3 & 18.2 \\
In vitro DM digestibility & 0.65 & 0.73 & 0.70 & 0.74 \\
In vitro OM digestibility & 0.65 & 0.73 & 0.69 & 0.74 \\
In vitro CP digestibility & 0.72 & 0.78 & 0.80 & 0.81 \\
\hline
\end{tabular}

${ }^{1}$ Grass hay-high forage $(\mathrm{GF})=70 \%$ of grass hay and $30 \%$ of concentrate; grass hay-high concentrate $(\mathrm{GC})=$ $30 \%$ of grass hay and $70 \%$ of concentrate; alfalfa hay-high forage $(\mathrm{AF})=70 \%$ of alfalfa hay and $30 \%$ of concentrate; alfalfa hay-high concentrate $(\mathrm{AC})=30 \%$ of alfalfa hay and $70 \%$ of concentrate (DM basis).

the present experiment were the same as those used in a previous experiment with goats (Cantalapiedra-Hijar et al., 2009), which allowed us to not only compare the fermentation parameters among fermenters receiving different diets at $2 \mathrm{~F} / \mathrm{B}$, but also to state the ability of fermenters with different $\mathrm{F} / \mathrm{B}$ to show response patterns to diets that are similar to what occur in the rumen of goats. Therefore, the effect of diet will be specifically discussed concerning the ability of $\mathrm{CCF}$ to discriminate diets as is done in vivo, as well as regarding its possible interaction with the $\mathrm{F} / \mathrm{B}$ used.

Because no $\mathrm{pH}$ control was conducted in the present experiment, the $\mathrm{pH}$ values (Figure 1 ) were the result of fermentable OM input and continuous infusion of artificial saliva. The $\mathrm{pH}$ values for each diet were similar across time, regardless the $\mathrm{F} / \mathrm{B}$ used $(\mathrm{F} / \mathrm{B} \times \operatorname{diet}$ $\times$ time $=0.83)$. An increase $(P<0.001)$ in the total VFA concentration and a decrease $(P<0.001)$ in the average $\mathrm{pH}$ (Table 2) were observed with increased $\mathrm{F} / \mathrm{B}$, in accordance with other studies using stratified (Muetzel et al., 2009), single-flow (Meng et al., 1999), and dual-flow (Hoover et al., 1976) CCF. Diet affected both the $\mathrm{pH}$ and VFA concentration $(P \leq 0.002)$, but the $\mathrm{F} / \mathrm{B} \times$ diet interaction $(P \leq 0.03)$ indicated that the response of $\mathrm{pH}$ and VFA concentration to diet varied according to the $\mathrm{F} / \mathrm{B}$ used. The results from Meng et al. (1999) obtained in single-flow CCF also showed that the $\mathrm{pH}$ and VFA concentration values for the experimental diets were ranked differently according to the F/B used. However, the different dilution rates achieved by infusing different volumes of buffer into the fermenters can explain the differences found in that study among the different $\mathrm{F} / \mathrm{B}$. A higher VFA concentration in CCF compared with that in the rumen is usually explained by the lack of absorption in vitro (Hannah et al., 1986; Mansfield et al., 1995; Devant et al., 2001), but it ultimately depends on the F/B used in fermenters, as shown in this study. The mean $\mathrm{pH}$ values obtained in this in vitro experiment $(6.22$ to 6.53) were within the range of those found in the rumen of goats (6.21 to 6.43) that were fed the same 4 diets (Cantalapiedra-Hijar et al., 2009), provided that fermenters were supplied diets at a low F/B (23.5 g of $\mathrm{DM} / \mathrm{L}$ ). In addition, $\mathrm{pH}$ values and the total daily VFA concentration showed a response pattern to diets similar to that observed in vivo (Cantalapiedra-Hijar et al., 2009), but this was only the case with fermenters with a low $\mathrm{F} / \mathrm{B}$. Therefore, the ability of fermenters to detect differences in VFA concentration among diets similar to those of the rumen seemed to depend on the $\mathrm{F} / \mathrm{B}$ used. These findings support the hypothesis that $\mathrm{F} / \mathrm{B}$ affects the incubation $\mathrm{pH}$ and suggest that some discrepancies found between rumen and $\mathrm{CCF}$ by direct in vivo-in vitro comparisons in some studies (Carro et al., 2009; Molina-Alcaide et al., 2009) could be minimized by adjusting the $\mathrm{F} / \mathrm{B}$ in the fermenters to attain $\mathrm{pH}$ values more comparable with those in the rumen.

Pronounced differences $(P<0.001)$ were found in the molar proportions of all individual VFA found in fermenters with high and low F/B. Because individual VFA molar proportions depend on the $\mathrm{pH}$ reached in CCF (Calsamiglia et al., 2002; Yang et al., 2002), it is not surprising that the interaction between the main effects on $\mathrm{pH}$ values was also found on all individual VFA molar proportions, with the exception of isoacids. Although diets supplied to fermenters at low $\mathrm{F} / \mathrm{B}$ promoted mean $\mathrm{pH}$ values close to those found in vivo (Cantalapiedra-Hijar et al., 2009), the acetate-topropionate ratios $(\mathbf{C 2} / \mathbf{C 3})$ were not within the same range (2.85-3.94 vs. 3.47-4.45 for in vitro and in vivo, respectively). These results may indicate that although the $\mathrm{pH}$ values in the fermenter may play an important 

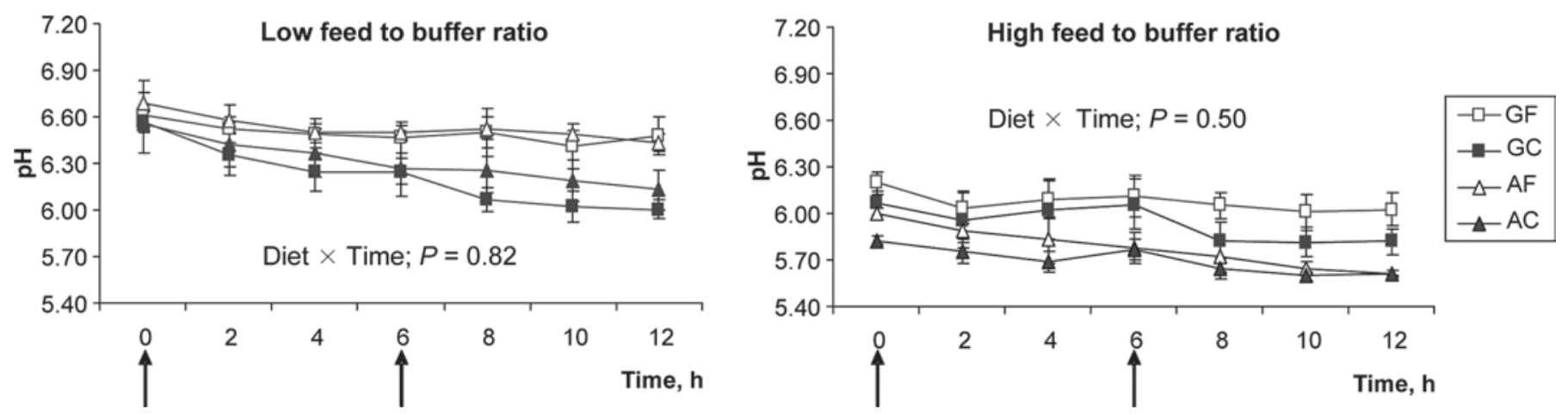

Figure 1. Variation of $\mathrm{pH}$ values with time after feeding $(\uparrow)$ in single-flow continuous-culture fermenters $(\mathrm{CCF})$ receiving the experimental diets at 2 different feed-to-buffer ratios (F/B): low $(23.5 \mathrm{~g}$ of DM/L) and high $(35 \mathrm{~g}$ of DM/L); grass hay-high forage (GF) diet $=70 \%$ of grass hay and $30 \%$ of concentrate; grass hay-high concentrate (GC) diet $=30 \%$ of grass hay and $70 \%$ of concentrate; alfalfa hay-high forage (AF) diet $=70 \%$ of alfalfa hay and 30\% of concentrate; alfalfa hay-high concentrate (AC) diet $=30 \%$ of alfalfa hay and $70 \%$ of concentrate (DM basis). Arrows show the feeding times. The $\mathrm{pH}$ values across time in fermenters with low and high $\mathrm{F} / \mathrm{B}$ were not different $(\mathrm{F} / \mathrm{B} \times$ diet $\times$ time $=0.83)$.

role in the in vitro fermentation profile (Calsamiglia et al., 2008), other in vitro-related factors such as the dilution rate (Crawford et al., 1980), content stratification (Muetzel et al., 2009), or the harvest and processing of fermenter inoculum (Ziemer et al., 2000) are also involved in the in vivo-in vitro discrepancies. The $\mathrm{C} 2 /$ C3 values found in this experiment were affected $(P$ $<0.001$ ) by both diet and F/B, but the experimental design did not allow us to clarify whether diet (Russell, 1998; de Veth and Kolver, 2001) or pH (Calsamiglia et al., 2008) influenced the $\mathrm{C} 2 / \mathrm{C} 3$ more. In many studies with $\mathrm{CCF}$, changes in the ruminal fermentation pattern as $\mathrm{pH}$ decreases have been largely ascribed to shifts in bacterial species (Yang et al., 2002; Colombatto et al., 2003; Carro et al., 2009). The effect of $\mathrm{F} / \mathrm{B}$ on ruminal fermentation parameters found in this study could be explained by a pH-mediated shift in the bacterial species present in the fermenters. Furthermore, the concentration of purine bases in EB (Figure 2) differed $(P<0.05)$ in fermenters with different $\mathrm{F} / \mathrm{B}$ for 3 out of 4 diets, supporting the hypothesis that changes in the $\mathrm{F} / \mathrm{B}$ can promote the presence of different bacterial species (Obispo and Dehority, 1999), which likely occurs through a pH-mediated effect.

Table 2. Average values of $\mathrm{pH}$, VFA concentration, and molar proportions in single-flow continuous-culture fermenters (CCF) receiving the experimental diets at 2 different feed-to-buffer ratios $(\mathrm{F} / \mathrm{B})^{1}$

\begin{tabular}{|c|c|c|c|c|c|c|c|c|c|c|c|c|}
\hline \multirow[b]{2}{*}{ Item } & \multicolumn{4}{|c|}{ Diet with low $\mathrm{F} / \mathrm{B}^{2}$} & \multicolumn{4}{|c|}{ Diet with high $\mathrm{F} / \mathrm{B}^{3}$} & \multirow[b]{2}{*}{ SEM } & \multicolumn{3}{|c|}{$P$-value } \\
\hline & GF & $\mathrm{GC}$ & $\mathrm{AF}$ & $\mathrm{AC}$ & GF & GC & $\mathrm{AF}$ & $\mathrm{AC}$ & & $\mathrm{F} / \mathrm{B}$ & Diet & $\mathrm{F} / \mathrm{B} \times \operatorname{diet}$ \\
\hline Average $\mathrm{pH}^{4}$ & $6.50^{\mathrm{a}}$ & $6.22^{\mathrm{b}}$ & $6.53^{\mathrm{a}}$ & $6.31^{\mathrm{b}}$ & $6.08^{\mathrm{w}}$ & $5.94^{\mathrm{x}}$ & $5.79^{y}$ & $5.70^{z}$ & 0.021 & $<0.001$ & 0.001 & 0.003 \\
\hline $\begin{array}{l}\text { Total VFA, }{ }^{5} \mathrm{mmol} / \mathrm{L} \\
\text { VFA, mol } 100 \mathrm{~mol}\end{array}$ & $112^{\mathrm{a}}$ & $115^{\mathrm{a}}$ & $125^{\mathrm{b}}$ & $120^{\mathrm{ab}}$ & $152^{\mathrm{x}}$ & $173^{\mathrm{y}}$ & $168^{\mathrm{xy}}$ & $166^{\mathrm{xy}}$ & 1.9 & $<0.001$ & 0.002 & 0.03 \\
\hline Acetate & $63.9^{\mathrm{ab}}$ & $62.1^{\mathrm{b}}$ & $65.1^{\mathrm{a}}$ & $63.0^{\mathrm{b}}$ & $57.1^{\mathrm{x}}$ & $49.7^{\mathrm{y}}$ & $63.5^{\mathrm{w}}$ & $50.6^{\mathrm{y}}$ & 0.47 & $<0.001$ & $<0.001$ & 0.001 \\
\hline Propionate & $21.0^{\mathrm{b}}$ & $22.4^{\mathrm{a}}$ & $16.6^{\mathrm{c}}$ & $20.9^{\mathrm{b}}$ & $22.3^{\mathrm{x}}$ & $27.8^{\mathrm{w}}$ & $21.8^{\mathrm{x}}$ & $28.7^{\mathrm{w}}$ & 0.26 & $<0.001$ & $<0.001$ & 0.002 \\
\hline Valerate & $1.65^{\mathrm{c}}$ & $2.26^{\mathrm{b}}$ & $2.93^{\mathrm{a}}$ & $2.65^{\mathrm{a}}$ & $2.42^{\mathrm{y}}$ & $2.64^{\mathrm{y}}$ & $2.94^{\mathrm{x}}$ & $3.54^{\mathrm{w}}$ & 0.061 & $<0.001$ & $<0.001$ & 0.01 \\
\hline C2/C3 ratio ${ }^{7}$ & $3.06^{\mathrm{b}}$ & $2.85^{\mathrm{b}}$ & $3.94^{\mathrm{a}}$ & $3.06^{\mathrm{b}}$ & $2.57^{\mathrm{x}}$ & $1.80^{\mathrm{y}}$ & $2.92^{\mathrm{w}}$ & $1.77^{\mathrm{y}}$ & 0.043 & $<0.001$ & $<0.001$ & 0.03 \\
\hline
\end{tabular}

${ }^{\mathrm{a}-\mathrm{c} ; \mathrm{w}-\mathrm{Z}} \mathrm{In}$ a row, within each $\mathrm{F} / \mathrm{B}$, means without a common superscript letter differ $(P<0.05)$; observations, $\mathrm{n}=4$.

${ }^{1}$ Grass hay-high forage $(\mathrm{GF})=70 \%$ of grass hay and $30 \%$ of concentrate; grass hay-high concentrate (GC) $=30 \%$ of grass hay and $70 \%$ of concentrate; alfalfa hay-high forage $(\mathrm{AF})=70 \%$ of alfalfa hay and $30 \%$ of concentrate; alfalfa hay-high concentrate $(\mathrm{AC})=30 \%$ of alfalfa hay and $70 \%$ of concentrate (DM basis).

${ }^{2}$ Low feed-to-buffer ratio $=23.5 \mathrm{~g}$ of $\mathrm{DM} / \mathrm{L}$.

${ }^{3}$ High feed-to-buffer ratio $=35 \mathrm{~g}$ of $\mathrm{DM} / \mathrm{L}$.

${ }^{4}$ Average $\mathrm{pH}$ at 0 to $12 \mathrm{~h}$ after the morning feeding measured every $2 \mathrm{~h}$.

${ }^{5}$ The VFA concentration was measured in effluents collected every morning before feeding from d 8 to 11 , representing 24 -h average values.

${ }^{6}$ Isobutyrate plus isovalerate.

${ }^{7}$ Acetate-to-propionate ratio. 


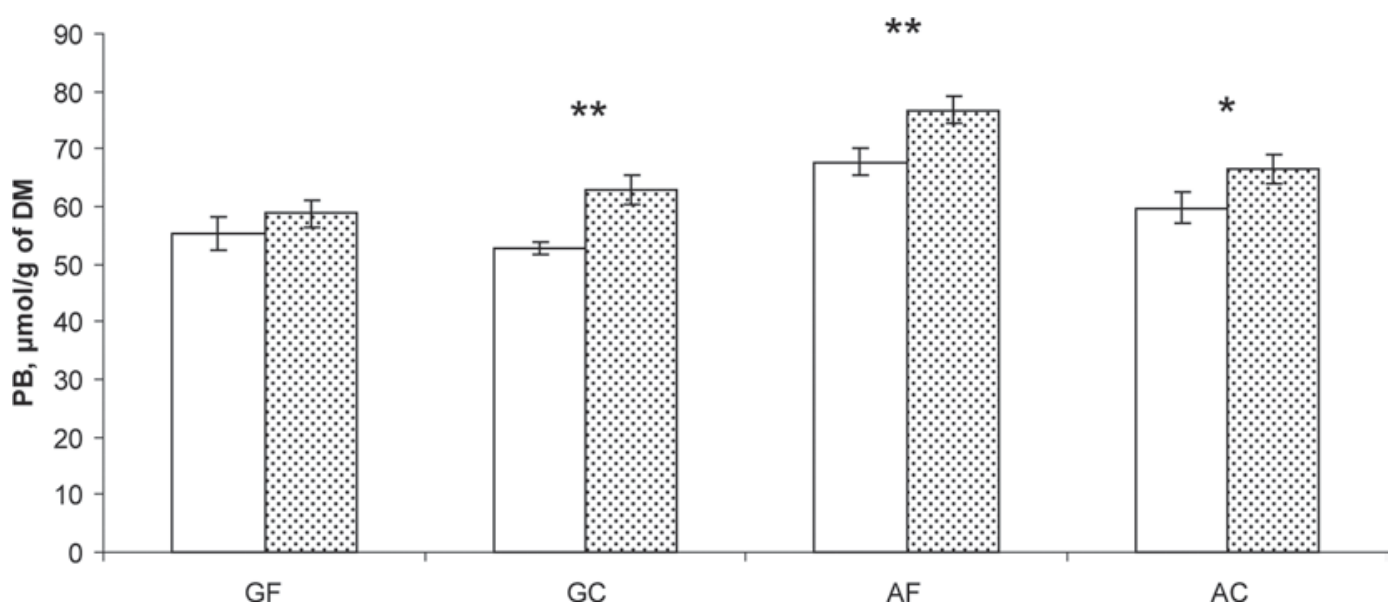

Figure 2. Purine bases $(\mathrm{PB})$ concentration $(\mu \mathrm{mol} / \mathrm{g}$ of $\mathrm{DM})$ in effluent bacteria isolated from single-flow continuous-culture fermenters (CCF) receiving the experimental diets at low (23.5 g of DM/L; open bars) and high (35 g of DM/L; dotted bars) feed-to-buffer ratio. Grass hay-high forage $(\mathrm{GF})$ diet $=70 \%$ of grass hay and $30 \%$ of concentrate; grass hay-high concentrate (GC) diet $=30 \%$ of grass hay and $70 \%$ of concentrate; alfalfa hay-high forage (AF) diet $=70 \%$ of alfalfa hay and $30 \%$ of concentrate; alfalfa hay-high concentrate (AC) diet $=30 \%$ of alfalfa hay and $70 \%$ of concentrate (DM basis). Asterisks indicate a significant difference between the 2 feed-to-buffer ratios used within the same diet $(*$ indicates $P<0.05 ; * *$ indicates $P<0.01)$. Number of observations per mean $=4$.

In order to illustrate to what extent the bacterial communities in CCF can change according to the F/B used, both the similarity and the diversity of bacterial composition in fermenters were assessed by T-RFLP. Because samples were submitted to digestion using 4 different enzymes and because the obtained profiles were combined, the results likely provide a more comprehensive profile of the diverse bacterial communities present in each sample. The use of more than one restriction enzyme has been shown to facilitate the resolution of bacterial populations (Liu et al., 1997; Marsh 1999) because different bacterial populations can share the same terminal restriction fragment length for a particular primer-enzyme combination but not for others (Marsh et al. 2000). Figure 3 shows the dendrogram based on Bray-Curtis distances and the Ward method analysis, the $\mathrm{pH}$ values in the fermenters, and the Shannon index for every sample. The dendrogram shows 2 well-defined clusters in which samples are almost completely separated according to the F/B used in the fermenters. Moreover, differences $(P<0.05)$ in fermenters belonging to these 2 clusters were found with regard to both the average $\mathrm{pH}$ (5.81 vs. 6.38) and bacterial diversity (3.09 vs. 3.42), suggesting a positive relationship between fermenter $\mathrm{pH}$ and bacterial diversity. Although a lower Shannon index does not necessarily mean a lower richness of bacterial species, the average number of peaks in the electropherograms obtained in this study for the 4 enzymes was numerically lower in the cluster corresponding to the fermenters with high $\mathrm{F} / \mathrm{B}$ than in the one grouping most fermenters with low F/B (152 vs. $172, P=0.06$; data not shown), which certainly would indicate a loss of bacterial species. The T-RFLP data analysis also revealed that the SIMPER for samples of high-F/B fermenters $(42.7 \%)$ was higher $(P=0.006)$ than that observed in samples of low-F/B fermenters $(36.2 \%)$, indicating a greater homogeneity in terms of the bacterial communities as the $\mathrm{F} / \mathrm{B}$ increases in $\mathrm{CCF}$. Therefore, the set of data shown in Figure 3 may indicate that the lower average $\mathrm{pH}$ reached in fermenters with high F/B (35 g of DM/L) could lead to a decrease in or disappearance of certain bacterial species compared with what occurs in fermenters with low $\mathrm{F} / \mathrm{B}(23.5 \mathrm{~g}$ of $\mathrm{DM} / \mathrm{L})$ and that this decrease in the number of species may involve a greater similarity in bacterial communities across diets in high-F/B fermenters. In addition, the reduced fiber digestibility in the high-F/B fermenters, discussed later, supports the hypothesis that the lower diversity found in fermenters with high $\mathrm{F} / \mathrm{B}$ in comparison with those with low $\mathrm{F} / \mathrm{B}$ could be partially due to the decrease in cellulolytic bacterial populations. On the other hand, the dendrogram shows no clustering based on the diet supplied to the fermenters, suggesting that diet composition does not have an obvious effect on the structure of the bacterial community in CCF. The lack of effect of diet on the microbial community composition in this in vitro study could be partially explained by the following factors: 1) the fermenters receiving the same treatment were inoculated with rumen fluid belonging to different goats, and 2) the standardized in vitro conditions among fermenters did not mimic the potential diet $x$ animal interactions, which might alter the saliva yield, buffering capacity, and rumen dilution rate, among 


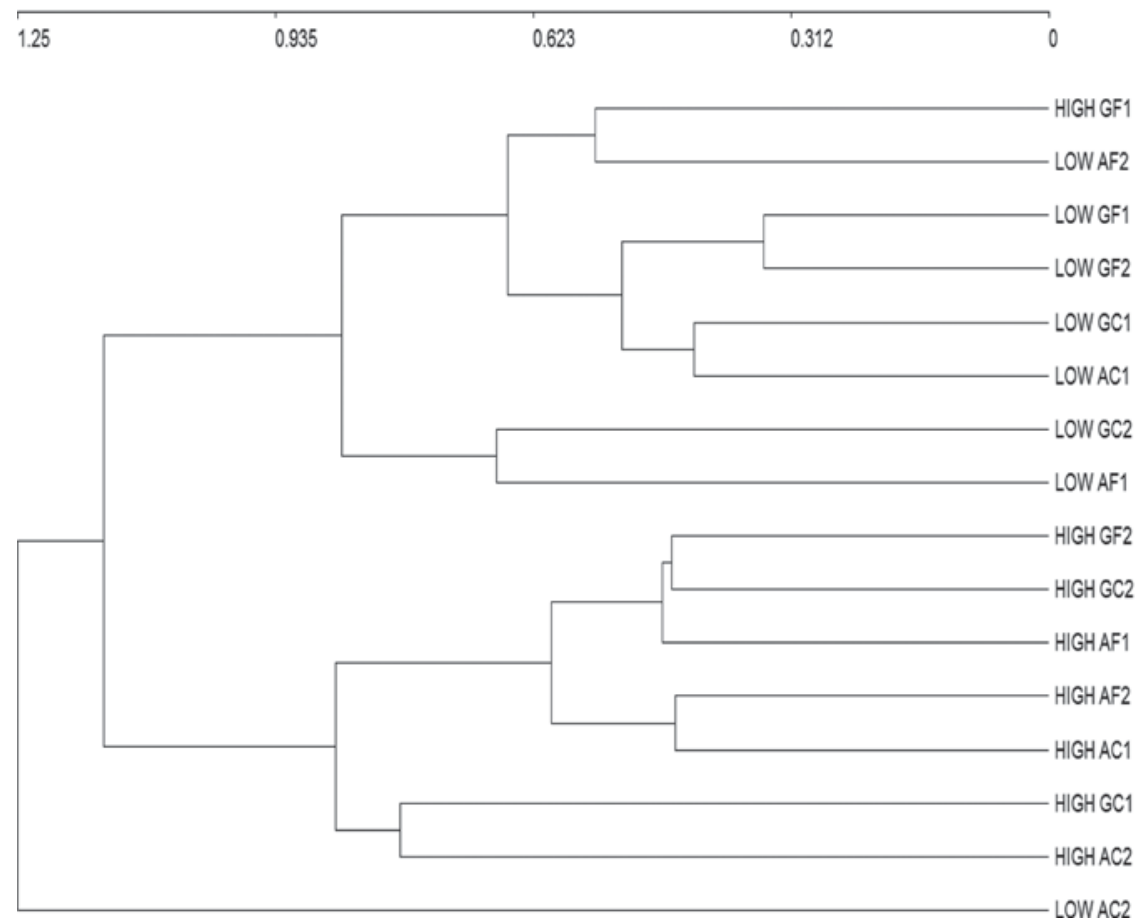

\begin{tabular}{|c|c|c|c|}
\hline $\mathrm{pH}$ & $\begin{array}{c}\text { Average } \\
\text { by cluster }\end{array}$ & $\begin{array}{c}\text { Shannon } \\
\text { Index }\end{array}$ & $\begin{array}{l}\text { Average } \\
\text { by cluster }\end{array}$ \\
\hline 6.09 & \multirow{8}{*}{$6.38^{\mathrm{a}}$} & 3.36 & \multirow{8}{*}{$3.42^{\mathrm{a}}$} \\
\hline 6.69 & & 3.62 & \\
\hline 6.36 & & 3.47 & \\
\hline 6.28 & & 3.47 & \\
\hline 6.27 & & 3.58 & \\
\hline 6.53 & & 3.31 & \\
\hline 6.03 & & 3.00 & \\
\hline 6.75 & & 3.55 & \\
\hline 5.99 & \multirow{7}{*}{$5.81^{\mathrm{b}}$} & 3.18 & \multirow{7}{*}{$3.09^{\mathrm{b}}$} \\
\hline 5.85 & & 3.20 & \\
\hline 5.87 & & 3.41 & \\
\hline 5.77 & & 3.19 & \\
\hline 5.64 & & 2.86 & \\
\hline 5.85 & & 2.75 & \\
\hline 5.73 & & 3.04 & \\
\hline 6.47 & & 3.17 & \\
\hline
\end{tabular}

Figure 3. Dendrogram illustrating the relationship among bacterial communities. Results of terminal RFLP (T-RFLP) analysis of fermenter contents were subject to Bray-Curtis distance analysis to elucidate relationships. Fermenters $(\mathrm{n}=8)$ were fed 1 of 4 diets at a low or high feedto-buffer ratio (F/B; 23.5 vs. 35 g of DM/L, respectively). Grass hay-high forage (GF) diet $=70 \%$ of grass hay and $30 \%$ of concentrate; grass hay-high concentrate (GC) diet $=30 \%$ of grass hay and $70 \%$ of concentrate; alfalfa hay-high forage (AF) diet $=70 \%$ of alfalfa hay and $30 \%$ of concentrate; alfalfa hay-high concentrate $(\mathrm{AC})$ diet $=30 \%$ of alfalfa hay and $70 \%$ of concentrate on a DM basis. Incubations were repeated (e.g., high GF1 and high GF2) to provide a total of 16 observations. Scaled bar above dendrogram indicates Bray-Curtis distances. Mean incubation $\mathrm{pH}$ and bacterial diversity measured by the Shannon index are indicated. Similarity percentages (SIMPER) were 36.3 and 42.7 for low and high $\mathrm{F} / \mathrm{B}$ fermenters, respectively $(P=0.006)$. ${ }^{\mathrm{a}, \mathrm{b}}$ Average $\mathrm{pH}$ and Shannon index values in the cluster without a common superscript letter differ $(P$ $<0.05)$.

other factors, and thus, decrease the potential to detect the effects of the diet used. The experimental design in this work involved the donor animal and the corresponding inoculated fermenter receiving the same diet. This ensured that the microbial ecosystem present in the inoculum was a result of the fermentation of the substrate incubated in the fermenter. This design has been used in in vivo-in vitro comparisons (Mansfield et al., 1995; Molina-Alcaide et al., 2009) and was supported by Bach et al. (2005), who highlighted the importance of the environment pre-existing in the rumen for accurate evaluations of different substrates in vitro. It is well accepted that each animal harbors a specific bacterial community (Winkler et al., 2007) and, thus, that the inherent differences among individuals as well as their distinctive responses to changes in diet make interpretation at this point more difficult. However, in spite of having the influence of animals and diets confounded, the experimental design allowed us to detect the effect of the $\mathrm{F} / \mathrm{B}$ on the bacterial structure in $\mathrm{CCF}$; in almost all cases, bacterial communities from the 2 fermenters supplied with the same diet and inoculated with rumen fluid from the same goat fell into 2 different clusters, and this certainly seems to be ascribed solely to the effect of $\mathrm{F} / \mathrm{B}$.

The digestibility of all of the studied nutrients decreased $(P<0.001)$ in fermenters as $\mathrm{F} / \mathrm{B}$ increased from 23.5 to $35 \mathrm{~g}$ of $\mathrm{DM} / \mathrm{L}$ (Table 3 ), likely due to the associated fall in $\mathrm{pH}$ (Crawford et al., 1980). Moreover, the effect of $\mathrm{F} / \mathrm{B}$ on the true $\mathrm{OM}$ and the apparent NDF digestibility changed according to the type of diet $(\mathrm{F} / \mathrm{B} \times \operatorname{diet}, P \leq 0.003)$, which is consistent with the same interaction found in the total VFA concentration, molar proportions of most individual VFA, and the average $\mathrm{pH}$. All of these $\mathrm{F} / \mathrm{B} \times$ diet interactions suggest that the amount of feed supplied to the fermenters for a given dilution rate could affect not only the fermentation parameters themselves but also response patterns to diets. Calsamiglia et al. (2008) have recently shown that the $\mathrm{pH}$ in $\mathrm{CCF}$ was the major determinant driving the changes in the true OM digestibility and was the sole source of variation in the apparent NDF digestibility when the $\mathrm{pH}$ values dropped below 6.0. The decrease $(9.1 \% \pm 2.31)$ in the true OM digestibility 
Table 3. Nutrient digestibility in single-flow continuous-culture fermenters (CCF) receiving the experimental diets at 2 different feed-to-buffer ratios $(\mathrm{F} / \mathrm{B})^{1}$

\begin{tabular}{|c|c|c|c|c|c|c|c|c|c|c|c|c|}
\hline \multirow[b]{2}{*}{ Item } & \multicolumn{4}{|c|}{ Diet with low $\mathrm{F} / \mathrm{B}^{2}$} & \multicolumn{4}{|c|}{ Diet with high $\mathrm{F} / \mathrm{B}^{3}$} & \multirow[b]{2}{*}{ SEM } & \multicolumn{3}{|c|}{$P$-value } \\
\hline & GF & GC & $\mathrm{AF}$ & $\mathrm{AC}$ & GF & $\mathrm{GC}$ & $\mathrm{AF}$ & $\mathrm{AC}$ & & $\mathrm{F} / \mathrm{B}$ & Diet & $\mathrm{F} / \mathrm{B} \times \operatorname{diet}$ \\
\hline \multicolumn{13}{|l|}{ True digestibility, \% } \\
\hline DM & $55.6^{\mathrm{a}}$ & $73.2^{\mathrm{c}}$ & $64.3^{\mathrm{b}}$ & $73.6^{\mathrm{c}}$ & $51.4^{\mathrm{x}}$ & $64.6^{\mathrm{z}}$ & $55.8^{\mathrm{xy}}$ & $61.5^{\mathrm{yz}}$ & 0.54 & $<0.001$ & $<0.001$ & 0.11 \\
\hline $\mathrm{OM}$ & $51.8^{\mathrm{a}}$ & $63.2^{\mathrm{c}}$ & $57.3^{\mathrm{b}}$ & $63.8^{\mathrm{c}}$ & $49.7^{\mathrm{y}}$ & $56.7^{\mathrm{z}}$ & $52.6^{\mathrm{yz}}$ & $55.6^{\mathrm{z}}$ & 0.37 & $<0.001$ & $<0.001$ & 0.002 \\
\hline NDF & $49.6^{\mathrm{a}}$ & $57.2^{\mathrm{b}}$ & $51.3^{\mathrm{a}}$ & $57.9^{\mathrm{b}}$ & 46.3 & 48.3 & 44.0 & 44.7 & 0.42 & $<0.001$ & $<0.001$ & 0.003 \\
\hline $\mathrm{ADF}$ & $51.2^{\mathrm{a}}$ & $55.7^{\mathrm{b}}$ & $48.3^{\mathrm{a}}$ & $55.1^{\mathrm{b}}$ & $44.5^{\mathrm{yz}}$ & $49.9^{z}$ & $43.0^{\mathrm{y}}$ & $46.1^{\mathrm{yz}}$ & 0.43 & $<0.001$ & $<0.001$ & 0.45 \\
\hline \multicolumn{13}{|l|}{ Apparent digestibility, \% } \\
\hline $\mathrm{NFC}^{4}$ & $41.5^{\mathrm{a}}$ & $55.1^{\mathrm{b}}$ & $53.3^{\mathrm{b}}$ & $58.4^{\mathrm{b}}$ & $38.1^{\mathrm{y}}$ & $53.7^{\mathrm{z}}$ & $48.0^{\mathrm{z}}$ & $54.0^{\mathrm{z}}$ & 0.81 & 0.001 & $<0.001$ & 0.47 \\
\hline
\end{tabular}

${ }^{\mathrm{a}-\mathrm{c} ; \mathrm{x}-\mathrm{z}} \mathrm{In}$ a row, within each $\mathrm{F} / \mathrm{B}$, means without a common superscript letter differ $(P<0.05)$; observations, $\mathrm{n}=4$. Superscripts a-c indicate differences among mean values for diets with low $\mathrm{F} / \mathrm{B}$ and superscripts $\mathrm{w}-\mathrm{Z}$ indicate differences among mean values of diets with high $\mathrm{F} / \mathrm{B}$.

${ }^{1}$ Grass hay-high forage (GF) $=70 \%$ of grass hay and 30\% of concentrate; grass hay-high concentrate (GC) $=30 \%$ of grass hay and $70 \%$ of concentrate; alfalfa hay-high forage $(\mathrm{AF})=70 \%$ of alfalfa hay and $30 \%$ of concentrate; alfalfa hay-high concentrate $(\mathrm{AC})=30 \%$ of alfalfa hay and $70 \%$ of concentrate (DM basis).

${ }^{2}$ Low feed-to-buffer ratio $=23.5 \mathrm{~g}$ of DM/L.

${ }^{3}$ High feed-to-buffer ratio $=35 \mathrm{~g}$ of $\mathrm{DM} / \mathrm{L}$.

${ }^{4}$ Calculated as: $\mathrm{NFC}=\mathrm{OM}-(\mathrm{NDF}-\mathrm{CP}-$ ether extract $)$.

with increased F/B seemed to be more the result of a reduction $(15.3 \% \pm 3.65)$ in NDF digestibility than in the apparent NFC digestibility $(7.0 \% \pm 1.94)$. The larger decrease in fiber digestibility in comparison with that of NFC as pH decreases is in agreement with observations from other studies with CCF (Shriver et al., 1986; de Veth and Kolver, 2001; Yang et al., 2002). The decrease in the digestibility of fiber compared with that of the NFC fraction may be due to the lower tolerance of cellulolytic microorganisms than that of amylolytic and saccharolytic microorganisms to low $\mathrm{pH}$ (Russell and Dombrowski, 1980). The results found by Russell and Dombrowski (1980) indicate that one of the major reasons for fibrolytic bacteria elimination in the rumens with low $\mathrm{pH}$ values is the increase in the energy requirements for bacteria maintenance, as in this scenario; bacteria need to maintain the proton-motive force across the membrane. This involves a reduced rate of replication, which may result in a wash-out of this microbial community from the fermenter. The disappearance of the fibrolytic bacteria as the $\mathrm{pH}$ decreases in vitro (Colombatto et al., 2003) could partially explain the lower bacterial diversity found in most of the fermenters with high $\mathrm{F} / \mathrm{B}$.

The effects of variations in $\mathrm{F} / \mathrm{B}$ and diet on $\mathrm{N}$ metabolism in fermenters are shown in Table 4. Total, microbial, and undegraded dietary $\mathrm{N}$ output increased $(P<0.001)$ as the $\mathrm{F} / \mathrm{B}$ increased due to the higher $\mathrm{N}$ input in fermenters with high vs. low $\mathrm{F} / \mathrm{B}$. However, the ammonia-N output was not affected $(P=0.11)$ by the $\mathrm{F} / \mathrm{B}$, which is likely because of the lower $(P<0.001)$ dietary $\mathrm{CP}$ degradation found in fermenters with high vs. low F/B. Lower CP degradation in dual-flow CCF as $\mathrm{pH}$ decreases has been reported elsewhere (Calsamiglia et al., 2002; Cerrato-Sánchez et al., 2008) and has been related to the association between the reduction in the digestibility of fiber and protein (Wallace and Cotta, 1989). Consequently, it seems that the lower $\mathrm{pH}$ values found in fermenters with high $\mathrm{F} / \mathrm{B}$ may have promoted a lower dietary CP degradation, mainly through a drop in fiber digestibility, as the proteolytic enzymes produced by rumen microorganisms are generally active across a wide range of $\mathrm{pH}$ values (Wallace and Cotta, 1989). Both the PB flow and the estimated microbial $\mathrm{N}$ flow differed $(P<0.001)$ among diets and increased $(P<0.001)$ with increases in $\mathrm{F} / \mathrm{B}$. The effect of diet on $\mathrm{PB}$ flow in fermenters with low $\mathrm{F} / \mathrm{B}$ was comparable to that found for the urinary purine derivatives excretion in goats fed the same diets (Cantalapiedra-Hijar et al., 2009), where the GF diet promoted a lower urinary excretion of purine derivatives compared with that of the other 3 diets due to a lower intake of N. Because the urinary purine derivative excretion in ruminants is highly correlated with the flow of PB to the duodenum (Pérez et al., 1996; Martín-Orúe et al., 1998), these results could indicate a better simulation of rumen fermentation in $\mathrm{CCF}$ with low $\mathrm{F} / \mathrm{B}$ compared with those with high $\mathrm{F} / \mathrm{B}$.

\section{CONCLUSIONS}

The results suggest that the F/B ratio used in singleflow CCF affects the community structure and diversity of the bacteria found in the fermenters. The shift in bacterial species seems to be responsible for most of the discrepancies in fermentation parameters found between fermenters with low and high $\mathrm{F} / \mathrm{B}$ ratios. Therefore, the amount of feed supplied to single-flow 
Table 4. Nitrogen metabolism in single-flow continuous-culture fermenters (CCF) receiving the experimental diets at 2 different feed-to-buffer $\operatorname{ratios}(\mathrm{F} / \mathrm{B})^{1}$

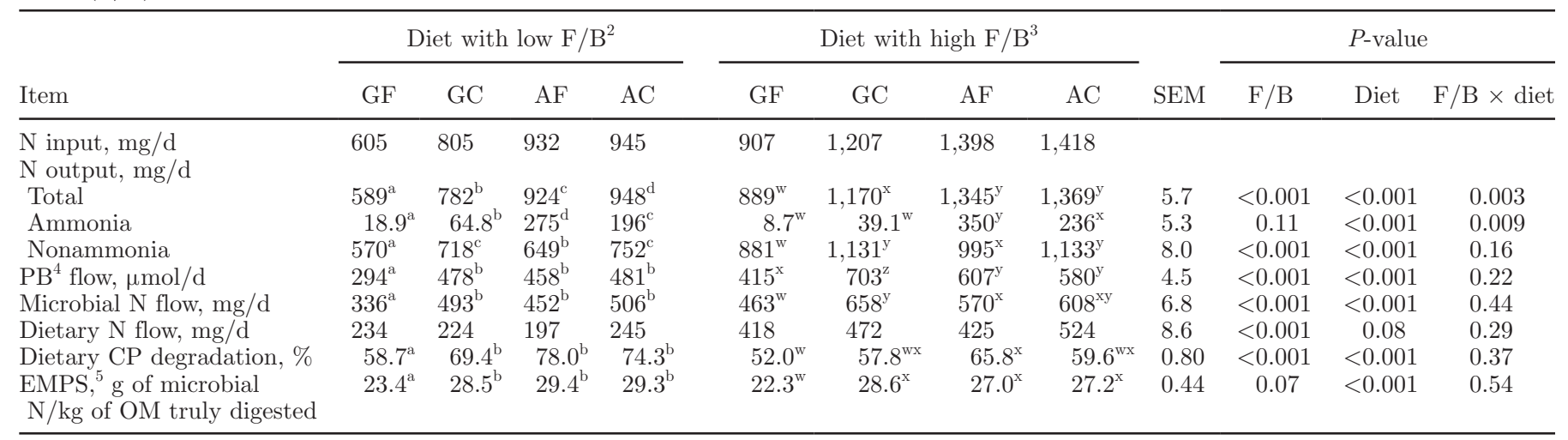

${ }^{\mathrm{a}-\mathrm{c} ; \mathrm{w}-\mathrm{Z}} \mathrm{In}$ a row, within each $\mathrm{F} / \mathrm{B}$, means without a common superscript letter differ $(P<0.05)$; observations, $\mathrm{n}=4$.

${ }^{1}$ Grass hay-high forage (GF) $=70 \%$ of grass hay and $30 \%$ of concentrate; grass hay-high concentrate (GC) $=30 \%$ of grass hay and $70 \%$ of concentrate; alfalfa hay-high forage $(\mathrm{AF})=70 \%$ of alfalfa hay and $30 \%$ of concentrate; alfalfa hay-high concentrate $(\mathrm{AC})=30 \%$ of alfalfa hay and $70 \%$ of concentrate (DM basis).

${ }^{2}$ Low feed-to-buffer ratio $=23.5 \mathrm{~g}$ of $\mathrm{DM} / \mathrm{L}$.

${ }^{3}$ High feed-to-buffer ratio $=35 \mathrm{~g}$ of $\mathrm{DM} / \mathrm{L}$.

${ }^{4}$ Purine bases.

${ }^{5}$ Efficiency of microbial protein synthesis.

$\mathrm{CCF}$ in which $\mathrm{pH}$ is not under control with regard to the infused buffer should be carefully chosen for the purpose of simulating ruminal fermentation.

\section{ACKNOWLEDGMENTS}

This research was supported by the Comisión Interministerial de Ciencia y Tecnología (CICYT) of Spain (Project AGL2004-04755-C02-02). Support from the Ministerio de Ciencia e Innovación for Formación de Profesorado Universitario (FPU) grant is gratefully acknowledged by G. Cantalapiedra. Thanks to J. Fernández, I. Jimenez, and V. Toledano at the Estación Experimental del Zaidín (Granada, Spain) for technical assistance and to B. Macias, E. Pinloche, and T. Blackmore at Aberystwyth University (Aberystwyth, UK) for data analysis support.

\section{REFERENCES}

AOAC. 2005. Association of Official Analytical Chemists. Official methods of analysis of the AOAC. 18th Ed. AOAC, Arlington, VA.

Bach, A., S. Calsamiglia, and M. D. Stern. 2005. Nitrogen metabolism in the rumen. J. Dairy Sci. 88:E9-E21.

Balcells, J., J. A. Guada, J. M. Peiró, and D. S. Parker. 1992. Simultaneous determination of allantoin and oxypurines in biological fluids by high-performance liquid chromatography. J. Chromatogr. 575:153-157.

Calsamiglia, S., P. W. Cardozo, A. Ferret, and A. Bach. 2008. Changes in rumen microbial fermentation are due to a combined effect of type of diet and pH. J. Anim. Sci. 86:702-711.

Calsamiglia, S., A. Ferret, and M. Devant. 2002. Effects of pH and pH fluctuations on microbial fermentation and nutrient flow from a dual-flow continuous culture system. J. Dairy Sci. 85:574-579.
Cantalapiedra-Hijar, G., D. R. Yáñez-Ruiz, A. I. Martín-García, and E. Molina-Alcaide. 2009. Effects of forage:concentrate ratio and forage type on apparent digestibility, ruminal fermentation, and microbial growth in goats. J. Anim. Sci. 87:622-631.

Carro, M. D., M. J. Ranilla, A. I. Martín-García, and E. MolinaAlcaide. 2009. Comparison of microbial fermentation of high- and low-forage diets in Rusitec, single-flow continuous-culture fermenters and sheep rumen. Animal 3:527-534.

Castillejos, L., S. Calsamiglia, A. Ferret, and R. Losa. 2005. Effects of a specific blend of essential oil compounds and the type of diet on rumen microbial fermentation and nutrient flow from a continuous culture system. Anim. Feed Sci. Technol. 119:29-41.

Cerrato-Sánchez, M., S. Calsamiglia, and A. Ferret. 2008. Effect of the magnitude of the decrease of rumen $\mathrm{pH}$ on rumen fermentation in a dual-flow continuous culture system. J. Anim. Sci. 86:378-383.

Church, D. C. 1976. Digestive Physiology and Nutrition of Ruminants. Vol. I. Digestive Physiology. D. C. Church, Corvallis, OR.

Colombatto, D., G. Hervás, W. Z. Yang, and K. A. Beauchemin. 2003. Effects of enzyme supplementation of a total mixed ration on microbial fermentation in continuous culture, maintained at high and low pH. J. Anim. Sci. 81:2617-2627.

Crawford, R. J. Jr., W. H. Hoover, and P. H. Knowlton. 1980. Effects of solids and liquid flows on fermentation in continuous cultures. I. Dry matter and fiber digestion, VFA production and protozoa numbers. J. Anim. Sci. 51:975-984.

Dahlberg, E. M., M. D. Stern, and F. R. Ehle. 1988. Effects of forage source on ruminal microbial nitrogen metabolism and carbohydrate digestion in continuous culture. J. Anim. Sci. 66:2071-2083.

de Veth, M. J., and E. S. Kolver. 2001. Diurnal variation in $\mathrm{pH}$ reduces digestion and synthesis of microbial protein when pasture is fermented in continuous culture. J. Dairy Sci. 84:2066-2072.

Devant, M., A. Ferret, S. Calsamiglia, R. Casals, and J. Gasa. 2001. Effect of nitrogen source in high-concentrate, low-protein beef cattle diets on microbial fermentation studied in vivo and in vitro. J. Anim. Sci. 79:1944-1953.

Griswold, K. E., G. A. Apgar, J. Bouton, and J. L. Firkins. 2003. Effects of urea infusion and ruminal degradable protein concentration on microbial growth, digestibility, and fermentation in continuous culture. J. Anim. Sci. 81:329-336.

Hannah, S. M., M. D. Stern, and F. R. Ehle. 1986. Evaluation of a dual flow continuous culture system for estimating bacterial fer- 
mentation in vivo of mixed diets containing various soya bean products. Anim. Feed Sci. Technol. 16:51-62.

Hongoh, Y., P. Deevong, T. Inoue, S. Moriya, S. Trakulnaleamsai, M. Ohkuma, C. Vongkaluang, N. Noparatnaraporn, and T. Kudo. 2005. Intra- and interspecific comparisons of bacterial diversity and community structure support coevolution of gut microbiota and termite host. Appl. Environ. Microbiol. 71:6590-6599.

Hoover, W. H., B. A. Crooker, and C. J. Sniffen. 1976. Effects of differential solid-liquid removal rates on protozoa numbers in continuous cultures of rumen contents. J. Anim. Sci. 43:528-534.

Isac, M. D., M. A. García, J. F. Aguilera, and E. Molina-Alcaide. 1994 A comparative study of nutrient digestibility, kinetics of digestion and passage and rumen fermentation pattern in goats and sheep offered medium quality forages at the maintenance level of feeding. Arch. Tierernahr. 46:37-50.

Littell, R. C., P. R. Henry, and C. B. Ammerman. 1998. Statistical analysis of repeated measures data using SAS procedures. J. Anim. Sci. 76:1216-1231.

Liu, W. T., T. L. Marsh, H. Cheng, and L. J. Forney. 1997. Characterization of microbial diversity by determining terminal restriction fragment length polymorphisms of genes encoding 16rRNA. Appl. Environ. Microbiol. 63:4516-4522.

Mansfield, H. R., M. I. Endres, and M. D. Stern. 1995. Comparison of microbial fermentation in the rumen of dairy cows and dual flow continuous culture. Anim. Feed Sci. Technol. 55:47-66.

Marsh, T. L. 1999. Terminal restriction fragment length polymorphism (T-RFLP): An emerging method for characterizing diversity among homologous populations of amplification products. Curr. Opin. Microbiol. 2:323-327.

Marsh, T. L., P. Saxman, J. Cole, and J. Tiedje. 2000. Terminal restriction fragment length polymorphism analysis program, a webbased research tool for microbial community analysis. Appl. Environ. Microbiol. 66:3616-3620.

Martín-Orúe, S. M., J. Balcells, F. Zakraoui, and C. Castrillo. 1998 Quantification and chemical composition of mixed bacteria harvested from solid fractions of rumen digesta: Effect of detachment procedure. Anim. Feed Sci. Technol. 71:269-282.

Martínez, M. E., M. J. Ranilla, S. Ramos, M. L. Tejido, and M. D. Carro. 2009. Effects of dilution rate and retention time of concentrate on efficiency of microbial growth, methane production, and ruminal fermentation in Rusitec fermenters. J. Dairy Sci. 92:3930-3938.

McDougall, E. I. 1948. Studies on ruminant saliva. The composition and output of sheep's saliva. Biochem. J. 43:99-109.

Meng, Q., M. S. Kerley, P. A. Ludden, and R. L. Belyea. 1999. Fermentation substrate and dilution rate interact to affect microbial growth and efficiency. J. Anim. Sci. 77:206-214.

Miettinen, H., and J. Setälä. 1989. Design and development of a continuous culture system to study rumen fermentation. J. Agric. Sci. Finland. 61:463-473.

Molina-Alcaide, E., M. R. Pascual, G. Cantalapiedra-Hijar, E. Y. Morales-García, and A. I. Martín-García. 2009. Effects of concentrate replacement by feed blocks on ruminal fermentation and microbial growth in goats and single-flow continuous-culture fermenters. J. Anim. Sci. 87:1321-1333.

Muetzel, S., P. Lawrence, E. M. Hoffman, and K. Becker. 2009. Evaluation of a stratified continuous rumen incubation system. Anim. Feed Sci. Technol. 151:32-43.

Obispo, N. E., and B. A. Dehority. 1999. Feasibility of using total purines as a marker for ruminal bacteria. J. Anim. Sci. 77:30843095 .
Osborn, A. M., E. R. B. Moore, and K. N. Timmis. 2000. An evaluation of terminal-restriction fragment length polymorphism ( $\mathrm{T}$ RFLP) analysis for the study of microbial community structure and dynamics. Environ. Microbiol. 2:39-50.

Pérez, J. F., J. Balcells, J. A. Guada, and C. Castrillo. 1996. Determination of rumen microbial-nitrogen production in sheep: A comparison of urinary purine excretion with methods using ${ }^{15} \mathrm{~N}$ and purine bases as markers of microbial nitrogen entering the duodenum. Br. J. Nutr. 75:699-709.

Russell, J. B. 1998. The importance of $\mathrm{pH}$ in the regulation of ruminal acetate to propionate ratio and methane production in vitro. J. Dairy Sci. 81:3222-3230.

Russell, J. B., and D. B. Dombrowski. 1980. Effect of pH on the efficiency of growth by pure cultures of rumen bacteria in continuous culture. Appl. Environ. Microbiol. 39:604-610.

Sait, L., M. Galic, R. A. Strugnell, and P. H. Janssen. 2003. Secretory antibodies do not affect the composition of the bacterial microbiota in the terminal ileum of 10-week-old mice. Appl. Environ. Microbiol. 69:2100-2109.

Shannon, C. E. and W. Weaver. 1963. The Mathematical Theory of Communication. University of Illinois Press, Urbana.

Shriver, B. J., W. H. Hoover, J. P. Sargent, R. J. Crawford Jr., and W. V. Thayne. 1986. Fermentation of a high concentrate diet as affected by ruminal pH and digesta flow. J. Dairy Sci. 69:413-419.

Tapia, M. O., M. D. Stern, R. L. Koski, A. Bach, and M. J. Murphy. 2002. Effects of patulin on rumen microbial fermentation in continuous culture fermenters. Anim. Feed Sci. Technol. 97:239-246.

Tilley, J. M. A., and R. A. Terry. 1963. A two-stage technique for the in vitro digestion of forage crops. J. Br. Grassl. Soc. 18:104-111.

Van Soest, P. J., J. B. Robertson, and B. A. Lewis. 1991. Methods for dietary fiber, neutral detergent fiber, and nonstarch polysaccharides in relation to animal nutrition. J. Dairy Sci. 74:3583-3597.

Wales, W. J., E. S. Kolver, P. L. Thorne, and A. R. Egan. 2004. Diurnal variation in ruminal $\mathrm{pH}$ on the digestibility of highly digestible perennial ryegrass during continuous culture fermentation. J. Dairy Sci. 87:1864-1871.

Wallace, R. J., and M. A. Cotta. 1989. Metabolism of nitrogen-containing compounds. Pages 217-250 in The Rumen Microbial Ecosystem. P. N. Hobson, ed. Elsevier Applied Science, New York, NY.

Weatherburn, M. W. 1967. Phenol-hypochlorite reaction for determination of ammonia. Anal. Chem. 39:971-974.

Winkler, P., D. Ghadimi, J. Schrezenmeir, and J. P. Kraehenbuhl 2007. Molecular and cellular basis of microflora-host interactions. J. Nutr. 137(3 Suppl 2):756S-772S.

Yang, W. Z., K. A. Beauchemin, and D. D. Vedres. 2002. Effects of pH and fibrolytic enzymes on digestibility, bacterial protein synthesis, and fermentation in continuous culture. Anim. Feed Sci. Technol. 102:137-150.

Zhang, R., V. Thiyagarajan, and P.-Y. Qian. 2008. Evaluation of terminal-restriction fragment length polymorphism analysis in contrasting marine environments. FEMS Microbiol. Ecol. 65:169-178.

Ziemer, C. J., R. Sharp, M. D. Stern, M. A. Cotta, T. R. Whitehead, and D. A. Stahl. 2000. Comparison of microbial populations in model and natural rumens using $16 \mathrm{~S}$ ribosomal RNA-targeted probes. Environ. Microbiol. 2:632-643. 